ROCZNIKI HUMANISTYCZNE

$\frac{\text { Tom LXIX, zeszyt } 6-2021}{\text { ZESZYT SPECJALNY }}$

DOI: https://doi.org/10.18290/rh21696s-3

JAN FABRY

WILKEN ENGELBRECHT

\title{
VANDAAG HEEFT HIJ WEER EEN PESTHUMEUR, WAT EEN KLERELIJER IS DAT TOCH! OVER DE HISTORISCHE INVLOED VAN PANDEMIEËN OP NEDERLANDSE VERWENSINGEN
}

\section{INLEIDING}

Iedereen heeft wel eens een slechte dag dat hij of zij met het verkeerde been uit bed is gestapt en het idee heeft dat die dag werkelijk alles tegenzit. De irritatie loopt op, het humeur wordt steeds zwartgalliger en dan is een vloekwoord snel gesproken. Dat geldt voor alle talen en culturen. Het is wel vrij specifiek dat Nederlanders met ziektes verwensen (Sanders en Tempelaars 11, Van der Meulen et al., Het Groot Nederlands Vloekwoordenboek). Vlamingen vloeken net als vrijwel alle andere Europeanen meestal met godsdienstige of fecale vloeken maar ook met (nette) lichaamsdelen. Nederlanders gebruiken ongeveer 200 ziekten die zij elkaar toewensen als zij een krachtterm nodig hebben - om die reden wordt soms wel eens gezegd dat het gevloek van de Vlamingen poëtischer is dan dat van de Nederlanders. Het gebruik van de ziekten in Nederland blijkt mede te variëren aan de hand van wat de laatste pandemie was.

Mgr JAN FABRY - asystent w Katedrze Języka Niderlandzkiego w Instytucie Językoznawstwa Katolickiego Uniwersytetu Lubelskiego Jana Pawła II i Katedrze Nederlandistiky w Univerzita Palackého v Olomouci; adres do korespondencji: Tř́ida 1. Máje 42, 77900 Olomouc, Czechy; e-mail: janfabry91@gmail.com; ORCID: https://orcid.org/0000-0003-0692-0732.

Prof. dr hab. WiLKEN ENGELBRECHT - kierownik Katedry Języka Niderlandzkiego w Instytucie Językoznawsta Katolickiego Uniwersytetu Lubelskiego Jana Pawła II; adres do korespondencji: Katolicki Uniwersytet Lubelski Jana Pawła II, Instytut Językoznawstwa, Al. Racławickie 14, 20-950 Lublin; e-mail: wilken.engelbrecht@kul.pl; ORCID: https://orcid.org/0000-0002-9058-8199. 
In deze bijdrage ${ }^{1}$ onderzoeken wij eerst waarom Nederlanders een grote voorkeur voor ziekten als krachttermen hebben. Daarna bekijken we kort de geschiedenis van pandemieën die van invloed waren op het (kracht)taalgebruik in samenhang met de hiermee verbonden krachttermen en de vergelijking ervan met het gebruik in Vlaanderen. Na een bespreking van de taboewaarde van deze termen wordt de bijdrage afgesloten met een korte discussie over de potentiële taboewaarde van het coronavirus.

\section{WAAROM BESMETTELIJKE ZIEKTEN ALS KRACHTTERM?}

Vaak wordt als reden om liever gebruik te maken van ziekten dan van bijvoorbeeld met het opperwezen gerelateerde termen de calvinistische achtergrond van Nederland aangegeven (Van Sterkenburg, Krachttermen). Als we echter bekijken welke Europese landen het meest calvinistisch zijn - in alfabetische volgorde zijn dat enkele Duitse gebieden, Hongarije, Nederland, Schotland en Zwitserland - blijkt alleen het Hongaars een duidelijke neiging tot het gebruik van ziekten als verwensing te hebben met krachttermen als "A rosseb egyen meg" (Krijg de pokken), "A fene egye meg" (Moge de ziekte hem opeten), "Frász essen belé" (Krijg de dysenterie) of "Hogy a görcs álljon beléd" (Krijg de krampen) (Cseresnyési). ${ }^{2}$

De achtergrond van de veronderstelde band tussen calvinisme en het gebruik van ziekten als krachttermen zou gelegen zijn in de idee van de predestinatie. God bepaalt immers of iemand ziek wordt of niet, waarmee ziekte dus een teken van Gods vervloeking is. Bovendien lijken calvinistische regio's traditioneel gezonder te zijn dan katholieke als gevolg van een soberdere en verantwoordelijkere levensstijl (Mackenbach). De traditionele formule in verband met ziekten is "Krijg de X", vergelijk het Hongaarse "A X egye(n) meg" of "X belé(d)". Deze formulering lijkt inderdaad in de zestiende eeuw samen met het calvinisme op te komen (Sanders en Tempelaars 55). Tom Ruette (229) wijst er echter op dat de formule al in de veertiende eeuw in Zuid-Duitsland werd gevonden. Uit zijn onderzoek naar het voorkomen van

\footnotetext{
${ }^{1}$ Deze bijdrage is tot stand gekomen dankzij het IGA-project FF 2021/003 The Correspondence of Wilhelm von Humboldt and its link with Belgium and the Netherlands van de Faculteit Letteren aan de Palacky Universiteit in Olomouc (Tsjechië).

${ }^{2}$ Als gevolg van het feit dat het Hongaars voor de meeste linguïsten een onbegrijpelijke taal is, wordt dit vaak buiten beschouwing gelaten. Zo stelt bijv, Ruette (229) dat verwensingen met ziekten verder voornamelijk in het Jiddisch en het Pools voorkomen. Het Hongaars blijkt echter een ruime variatie aan ziekteverwensingen te hebben.
} 
ziekteverwensingen blijkt wel dat deze inderdaad vooral voorkomen in overwegend calvinistische regio's van Nederland en dan met name in de Randstad en, opmerkelijk, in Den Bosch en omgeving. Het is onduidelijk of dit vooral met calvinisme of met een specifiek Amsterdamse merkwaardigheid te maken heeft (Ruette 240-41). De concentratie in Amsterdam en de Randstad lijkt verband te houden met het feit dat een ernstig besmettelijke ziekte krijgen betekent dat de bewuste persoon economisch (tijdelijk) niet meer mee kan tellen en dus sociaal uitgerangeerd wordt.

\section{PANDEMIEËN IN DE NEDERLANDSE GESCHIEDENIS}

De vaakst toegewenste ziekten zijn, met uitzondering van kanker, alle van het type ernstig besmettelijke pandemie. In chronologisch volgorde gaat het om de pest, de pokken, de cholera en de tuberculose ${ }^{3}$ (Sanders en Tempelaars 23). Interessant is dat de populariteit van samenstellingen in verwensingen met deze ziekten inderdaad samenhangen met de periodes, waarin deze ziekten heersten. Voor de oudste genoemde pandemie - de pest - weten we bij gebrek aan materiaal niet wanneer de vloeken opkwamen, maar alle andere behandelde krachttermen zijn in zwang geraakt tijdens de pandemieën die de termen hebben opgeroepen. We lopen de belangrijkste hier even na.

\subsection{De pest}

De pest deed in de Nederlanden in 1348 haar intrede en was pas begin achttiende eeuw verdwenen. De eerste grote uitbraak in 1348/9 heeft Vlaanderen min of meer vermeden, maar in later eeuwen sloeg de Zwarte Dood ook daar toe. De laatste grote uitbraak was in 1663/4 in Amsterdam. Dat was de golf, waaraan Rembrandts geliefde Hendrickje Stoffels stierf.

Juist het feit dat veel geestelijken deze ziekte als Gods straf zagen (Noordegraaf en Valk 110-15) én het feit dat tijdens pestepidemiejaren in Amsterdam en Holland tot ruim het dubbele aantal mensen meer stierf dan gebruikelijk (53-59), hetgeen voor aanzienlijke economische problemen zorgde als gevolg van zowel sterfgevallen als ook preventieve overheidsmaatregelen die wij tegenwoordig als lockdown (met o.a. veel faillissementen in de horeca) zouden aanduiden (136-42), maakt het meer dan waarschijnlijk dat de vele verwensingen met "pest" inderdaad effectieve krachttermen waren. Uit de

\footnotetext{
${ }^{3}$ In de volksmond $k(o)$ le(e)re en tering. De tyfus laten we hier buiten beschouwing, omdat dit geen echt pandemische ziekte is.
} 
gegevens van Leo Noordegraaf en Gerrit Valk blijkt dat de pest in het dichtbevolkte Holland meer slachtoffers maakte dan elders, hoewel in het algemeen het levensniveau in niet-epidemische jaren juist veel beter was. Dit komt ijselijk nauwkeurig overeen met de ervaringen van de Covid-pandemie van 2020/1, tijdens welke deze in Nederland en met name in de Randstad veel grimmiger om zich heen greep dan bijvoorbeeld in Duitsland, na een aanvankelijk "langzame" start. Het Woordenboek der Nederlandse Taal (Boekenoogen en Van Lessen 1373-75) vermeldt de oudste toepassingen van "pest" in verband met verwensingen uit de zestiende eeuw.

Zoals Marten van der Meulen in een interview met Het Parool (Obdeijn) opmerkte, moet een scheldwoord ook "lekker bekken". Er is dan ook geen vloek "krijg de zwarte dood" bekend. Vanwege de homonymie met het werkwoord pesten in de zin van "treiteren", op zich eveneens van de ziekte afgeleid, kunnen we met pest- uiterst vervelende situaties of gevoelens als een pestzaak, een pesthumeur of een pestbui aanduiden, maar ook personen als een pestvent of pestmeid betitelen. Waar de toestanden rechtstreeks met de ziekte verband houden in de zin van 'buitengewoon onaangenaam', is bij personen de afgeleide betekenis van "treiteren" van belang.

\subsection{De pokken}

De pokken zijn een in Europa inheemse ziekte die tot aan het opkomen van inentingen eind achttiende eeuw jaarlijks veel slachtoffers maakte, maar vooral in de achttiende eeuw kennelijk de kans kreeg na het vrijwel verdwijnen van de pest. ${ }^{4}$ Waar de combinatie van pest- vooral op toestanden wordt betrokken - pestweer, pesthumeur - wordt pokken- meer op personen betrokken pokkenkerel, pokkenwijf, pokkenhoer, waarschijnlijk omdat de overlevenden duidelijk door de pokken getekend waren.

Volgens het Woordenboek der Nederlandse Taal (Van Lessen 3053-55) dat een flinke lijst met verwensingen met pokken noteert, waren verwensingen met pokken frequenter dan die met pest. Hoewel het $W N T$ al verwensingen bij Gerbrand Adriaensz Brederoo (1585-1618) noteert, zijn de oudste vermeldingen meestal uit de achttiende eeuw. Ewout Sanders en Rob Tempelaars (23) constateren overigens dat pest en pokken, "zeker als we dat met vroeger vergelijken, enigszins op hun retour" zijn. Het zijn nu eenmaal in de moderne tijd geen veel voorkomende ziektes meer.

\footnotetext{
${ }^{4}$ Veel medici en ook het Rijksinstituut voor Volksgezondheid en Milieu (www1) stelden vast dat in 2020/1 het griepvirus goeddeels verdwenen lijkt. Er is kennelijk plaats voor maar één vergelijkbare epidemische ziekte tegelijk.
} 


\subsection{Cholera}

De cholera, in de volksmond kolere genoemd, kwam rond 1830 in Europa aan en maakte vooral in het midden en tegen het einde van de eeuw veel slachtoffers. De samenstellingen met klere- zijn nog altijd zeer productief. Overigens leiden Sanders en Tempelaars (28-29) het populaire klere eerder van het Franse "colère" af (letterlijk 'woede', overdrachtelijk voor 'gal'), maar noteren wel dat het voorvoegsel juist zo geliefd is, omdat het gewone volk dit met de cholera in verband brengt.

De cholera werd in Europa met het aanleggen van drinkwaterleidingnetwerken en betere hygiëne goeddeels bedwongen, maar als scheldwoord is klere- onverminderd populair gebleven. De combinatie kan zowel voor een situatie klerezooi, klereweer - als voor personen-klerelijer, kleretrut - worden gebruikt.

\subsection{Tuberculose}

De tuberculose (tbc), ook wel pleuris, wat longvliesontsteking betekent, was een endemische ziekte die vanaf midden negentiende eeuw tot midden twintigste eeuw enorm veel slachtoffers maakte tot in de hoogste klassen van de bevolking. De ziekte tast vooral de longen aan, zorgt voor hardnekkige en vaak bloederige hoest, en veroorzaakt uittering van de zieke, vandaar de volksnaam tering. De ernstige variant, de vliegende tering, zorgde voor een spoedige dood. "Krijg de vliegende tering" was dus een vrij grove verwensing. Het $W N T$ (Heinsius 1574-75) vermeldt de oudste verwensingen uit het midden van de negentiende eeuw. Verwensingen met tering-zijn nog altijd buitengewoon populair en productief (Sanders en Tempelaars 74-75). Net als klere- wordt tering- zowel in situaties - teringzooi, teringbende - als voor personen teringhond, teringtrut - worden gebruikt. Daarnaast kan ook iemands humeur (teringhumeur, teringhekel) ermee worden aangeduid.

\subsection{Vlaamse "variant"}

Wanneer de Vlamingen vloeken komen minder verwensingen van ziekten naar buiten dan bij de Nederlanders - het gebruik van het woord kanker is wel een gemeenschappelijk goed -, maar Vlamingen zijn op hun beurt dan weer dominanter in het gebruik van kus, lik, en schijt (Sanders en Tempelaars 11). Voorts gebruiken de Vlamingen ook meer dan hun noordelijke taalgenoten genitaliën om te vloeken en zijn grappen in verband met seks of over andermans moeder en zijn/haar eigen schoonmoeder ook een vaak voorkomende manier 
om iemand te verwensen - zoals hierboven reeds aangetoond is dit niet louter een fenomeen dat in Vlaanderen aanwezig is. Het is afwachten in hoeverre de corona-epidemie een invloed zal hebben op het Vlaamse kleurrijke vloekpanorama, hetgeen voor een groot deel te maken heeft met de taboewaarde van de gehanteerde uitdrukking.

\section{DE TABOEWAARDE}

De kracht en werking van scheldwoorden en verwensingen ligt in hun taboewaarde, dat wil zeggen als hoe aanstootgevend of beledigend ze worden ervaren. Zoals Jan Pieter van Oudenhove en zijn collega's ("Wichser, klootzak", "Eikels en trutten over de grens") hebben vastgesteld, is dit sterk cultuurafhankelijk. Met de nodige simplificatie gezegd komt het hierop neer dat vervelende individuen in katholieke landen als Spanje en Italië graag naar de hel of de duivel worden verwezen, terwijl opmerkelijk gezien ook het lutherse Noorwegen met allerlei varianten van de duivel werkt. In zuidelijke landen met een sterk collectief bewustzijn is verwensing van iemands moeder een buitengewoon effectieve belediging, vooral in samenhang met een met deze uitgevoerde seksuele handeling.

Lexicoloog Piet van Sterkenburg (Vloeken 33) heeft in 2007 de frequentie van vloeken en verwensingen gemeten. De hoogstfrequente bleken het anale Je kunt de pot op en het seksuele Kus(t) mijn kloten te zijn, maar onder de 14 meest frequente bleek de helft met ziekten samen te hangen, waaronder (nr. 3) de k(o)lere, (nr. 4) de tering en (nr. 13) de pest. Bij de meest frequente Vlaamse verwensingen bleken ziekten afwezig. Uit het onderzoek van Lisa Verbeek (43-44) bleek dat zowel jongeren als ouderen de hoogste taboewaarde aan verwensingen met ziekten toekennen. Dit komt overeen met wat Piet van Sterkenburg (Vloeken 41) heeft vastgesteld: ziekten scoren qua taboewaarde hoog.

\section{CORONA?}

Er zijn wel meer ziekten als de tyfus en de kanker die geliefd zijn in samenstellingen met scheldwoorden of in verwensingen, maar deze behoren niet tot het groepje pandemieën. De huidige covid-pandemie heeft alles in zich om tot scheldwoord en verwensing te evolueren: het gaat om een ernstige en 
zeer besmettelijke ziekte, waarvan de pandemie grote economische schade veroorzaakt en die grote lage van de bevolking treft. De maatregelen romdom de ziekte richten vrij veel economische schade aan en kennen verhitte discussies tot in het parlement toe tussen voor- en tegenstanders.

\subsection{Corona, digitale evolutie en politiek}

Ten opzichte van voorgaande pandemieën is er in de huidige pandemie sprake van een extra element, dat in lijn ligt met de eerdergenoemde parlementaire debatten, namelijk de rol van de geneeskunde, en meer specifiek de virologen en de epidemiologen. In de huidige digitale en hoogtechnologische ${ }^{5}$ wereld zijn zij een vaak geziene gast in debatprogramma's om hun boodschap aan de bevolking te brengen via deze nieuwe kanalen, en worden zij ook uitgenodigd voor ontspanningsprogramma's. Niet iedereen is echter blij met de frequente aanwezigheid van specialisten ter zake, die vaak verweten worden zich buiten hun eigen wetenschappelijke domein te begeven, om op die manier de politiek te beïnvloeden. Deze kleine groep specialisten wordt door bepaalde politici zeer kritisch bekeken en om de acties van de virologen te benoemen en duidelijk af te keuren werden creatieve termen gevonden zoals bierviltjesvirologie en, eerder naar een persoon gericht, is er sprake van een amateurviroloog. ${ }^{6}$ Omdat virologen vaak bleven hameren op de noodzaak van de scherpe maatregelen, werden ze verder nog beschreven als coronazi's, een samenstelling tussen de ziekte corona en de afkorting van de politieke term nationaalsocialisme.

Een andere samenstelling die niet noodzakelijk met de virologen samenhangt is die van de covidioot, hetgeen niet meer is dan een scheldwoord voor iemand die de maatregelen tegen de verspreiding van COVID-19 volstrekt negeert. Covidioot was in Vlaanderen zelfs zodanig populair dat het in de "hitlijst" stond voor Woord van het Jaar 2020 in de Vlaamse krant De Standaard. Het woord heeft het echter moeten afleggen tegen "knuffelcontact". Alle "deelnemende woorden" hielden overigens verband met de coronapandemie, maar in de lijst vinden we geen enkel ander woord terug dat kan gecategoriseerd worden als een scheldwoord.

Ook de politici moeten het, pandemie of geen pandemie, ontgelden tijdens corona, niet omdat ze een nieuwe regel in gang hebben gezet, maar omdat ze

${ }^{5}$ Zo verscheen een (deel van een) Twittergesprek tussen de Belgische viroloog Marc van Ranst (*1965) en de Nederlandse coronascepticus Willem Engel (*1977) op posters in Nederlandse bushokjes.

${ }^{6}$ Marc van Ranst heeft, dankzij zijn actieve Twittergebruik en zijn pittige discussies met vooraanstaande politici van vooral rechtse stempel, het etiket van "Groot-Viroloog" meegekregen voor zijn (te grote) invloed op het politieke debat. 
te snel zouden versoepelen. Met dank aan de virologen, die hier vaak op hebben gewezen, wordt er smalend verwezen naar de ministers en staatssecretarissen van de regering als zijnde leden van de "soepelbrigade". Dit valt echter nog goed mee met de scheldwoorden die ze op sociale media terug kunnen vinden.

\subsection{Is corona een blijver?}

Volgens de mening van Rob Tempelaars (Obdeijn), een van de specialisten in scheldwoorden, heeft corona een vergelijkbaar hoge taboewaarde als de voornoemde hoogst besmettelijke volksziekten. Bovendien heeft het woord corona een vergelijkbare klankwaarde met de hierboven behandelde groep. Een laatste maar niet onbelangrijk element dat ervoor zou kunnen zorgen dat we corona over enkele jaren niet uit het scheldwoordenboek zouden kunnen schrappen is de populariteit van het gelijknamige bier. Hoewel er geen enkele link bestaat tussen de ziekte en deze alcoholische drank, verhoogt het gebruik van dezelfde term de kans dat de ziekte corona en de scheldwoorden die hiermee gepaard gaan, collectief in ons geheugen gegrift zullen blijven. Verder is er nog een element dat in de laatste jaren in opgang is gekomen en dat ook een invloed kan hebben op de verwensingen.

\subsection{Globalisering}

Een evolutie die al langer gaande is en die we kunnen koppelen aan de digitalisering is de globalisering en de taal waarin deze meestal plaatsvindt, namelijk het Engels. Zo is het Engelse woordje fuck multi-inzetbaar: het kan gebruikt worden als werkwoord, zelfstandig naamwoord en ook als adjectief (Van der Meulen et al., Het Groot Vlaams Vloekwoordenboek 16). In Nederland en Vlaanderen zien we deze verengelsing ook in de straat opduiken, zoals bijvoorbeeld reclames die (enkel) in het Engels worden geschreven of bijvoorbeeld ook bij vacatures. Een verschil met Nederland is natuurlijk dat in Vlaanderen ook Franse woorden ingang krijgen. Buitenlandse taaltherapie kan dus goed doen!

\section{CONCLUSIE}

Elders in deze aflevering behandelt Bas Hamers neologismen die met corona/covid van doen hebben. In deze bijdrage wilden wij bekijken welke invloed voorgaande pandemieën die Nederland hebben getroffen hebben 
gehad. De neologismen in de volkstaal, ofwel het Algemeen Onbeschaafd Nederlands, zoals de taalkundigen Heidi Aalbrecht en Pyter Wagenaar (2013) het enkele jaren geleden hebben gedoopt, liggen eerder in de sfeer van de krachttermen. En inderdaad, het begrip coronalijer en de verwensing Krijg de corona zijn al in de wiktionary genoteerd en op internet kunnen scheldwoorden als coronakop en een coronahufter - voor iemand die weigert voldoende afstand te houden of een mondkapje te dragen - al worden aangetroffen. Specifiek Noord-Nederlands is de neiging om krachttermen te stapelen. In navolging van wat Sanders en Tempelaars over andere gestapelde ziektevloeken stellen (11-12) zijn kankercorona en klerecorona al op het internet als krachttermen gevonden.

Of corona zich als scheldwoord zal doorzetten, hangt van veel factoren af, met name van hoe nadrukkelijk de ziekte in de samenleving aanwezig zal blijven. Zo heeft de Spaanse griep van goed een eeuw geleden het niet tot opname in de scheldwoordenfamilie gehaald: de kolere was nog nauwelijks onderdrukt, de tering nog volop aanwezig en "Spaanse griep" klinkt nu eenmaal niet kort en krachtig, hoewel het aantal slachtoffers enorm was (Van Wijdeven). Maar vooralsnog lijkt de uitdrukking Krijg de corona ons een blijvertje voor de toekomst in de beste Randstadtraditie.

\section{GECITEERDE WERKEN}

Aalbrecht, Heidi \& Pyter Wagenaar. Woordenboek van het Algemeen Onbeschaafd Nederlands. Unieboek/Het Spectrum, 2013.

Boekenoogen, Gerrit J. \& Jacoba H. van Lessen, redacteuren. Woordenboek der Nederlandsche Taal. Twaalfde deel, eerste stuk. P-Pletseren. Martinus Nijhoff \& A. W. Sijthoff, 1931.

Cseresnyési, László. “A káromkodás gyönyörüsége.” Magyar Narancs, 5 feb. 2012, www.magyarnarancs.hu/egotripp/a-karomkodas-gyonyorusege-78138. Opgevraagd 16 jun. 2021.

Groot, Hans de, redacteur. Van Dale Uitdrukkingen. Van Dale Lexicografie, 2004.

Heinsius, Jacob, redacteur. Woordenboek der Nederlandsche Taal. Zestiende deel. Stri-Tiend. Martinus Nijhoff \& A. W. Sijthoff, 1934.

Mackenbach, Johan. "Jean Calvin, Calvinism, and Population Health: Impressions from Switzerland." The European Journal of Public Health, jrg. 17, nr. 1, 2007. DOI: 10.1093/eurpub/ck1277.

Knuttel, Joannis A., editor. Woordenboek der Nederlandsche Taal. Derde deel, tweede stuk. C-Ehem. Martinus Nijhoff \& A. W. Sijthoff, 1916.

Lessen, Jacoba H. van, redacteur. Woordenboek der Nederlandsche Taal. Twaalfde deel, tweede stuk. Pletten-Quoyer. Martinus Nijhoff \& A. W. Sijthoff's, 1949.

Meulen, Marten van der, Fieke Van der Gucht, Rob Verlinden en Willem van Beylen, redacteuren. Het Groot Nederlands Vloekwoordenboek. Slimmer schelden en vaardiger vloeken. Lannoo, 2018. 
Meulen, Marten van der, Fieke Van der Gucht, Rob Verlinden en Willem van Beylen, redacteuren. Het Groot Vlaams Vloekwoordenboek. Slimmer schelden en vaardiger vloeken. Lannoo, 2018.

Noordegraaf, Leo, en Gerrit Valk. De gave Gods: de pest in Holland vanaf de middeleeuwen. Bert Bakker, 1996.

Obdeijn, Laura. "Eindigt Corona straks ook als scheldwoord?" Het Parool, 22 jun. 2020, www.parool.nl/ nederland/nederlanders-schelden-graag-met-ziektes-eindigt-corona-ook-als-scheldwoord b08a7e34. Opgevraagd 13 jun. 2021.

Oudenhoven, Jan Pieter van, Boele de Raad en Merle Hofstede. 2004. "Wichser, klootzak, cabrón. Schelden in Duitsland, Nederland en Spanje." Onze Taal, jrg. 73, 2005, pp. 156-158.

Oudenhoven, Jan Pieter van, Boele de Raad en Merle Hofstede. "Eikels en trutten over de grens. Scheldgedrag in elf landen in kaart gebracht." Nemo Kennislink, 1 sep. 2008, www.nemokennislink.nl/ publicaties/eikels-en-trutten-over-de-grens. Opgevraagd 14 jun. 2021.

Ruette, Tom. "Why Do the Dutch Swear with Diseases?" Linguistic Taboo Revisited, edited by Andrea Pizarro Pedraza, De Gruyter, 2018, pp. 225-243. DOI: 10.1515/9783110582758-012.

Sanders, Ewout, en Rob Tempelaars. Krijg de vinkentering! 1001 Nederlandse en Vlaamse verwensingen. Contact, 1998.

Sterkenburg, Piet van. Krachttermen: Scheldwoorden, vervloekingen, verwensingen en bezweringen. Scriptum, 2008.

Sterkenburg, Piet van. Vloeken is niet meer wat het geweest is. VUBPress, 2008.

Verbeek, Lisa. De kracht van sukkels, teringlijers en klootzakken. Attitudeonderzoek naar de taboewaarde van drie categorieën scheldwoorden onder ouderen en jongeren. Bachelorscriptie, Universiteit Utrecht, 2015, dspace.library.uu.nl/handle/1874/321916. Opgevraagd 15 jun. 2021.

Wijdeven, Ivo van. "De Spaanse griep in Nederland." Historisch Nieuwsblad, 14 apr. 2020, www.historischnieuwsblad.nl/de-spaanse-griep-in-nederland. Opgevraagd 16 jun. 2021.

\section{WEBSITES}

WikiWoordenboek, nl.wiktionary.org.

Rijksinstituut voor Volksgezondheid en MilieuMinisterie van Volksgezondheid, Welzijn en Sport, www.rivm.nl/griep-griepprik/feiten-en-cijfers. Actualisatie 26 mei 2021. Opgevraagd 16 jun. 2021.

\section{VANDAAG HEEFT HIJ WEER EEN PESTHUMEUR, WAT EEN KLERELIJER IS DAT TOCH! OVER DE HISTORISCHE INVLOED VAN PANDEMIEËN OP NEDERLANDSE VERWENSINGEN}

$$
\text { S a menvatting }
$$

In recente literatuur wordt geconstateerd dat de moderne mens steeds vaker vloekt en grove taal met ziektetermen er duidelijk de overhand hebben. Het artikel gaat in op de impact van eerdere pandemieën op Nederlanders. Na een korte historische inleiding wordt ingegaan op de lexicale sporen van de verschillende pandemieën.

Trefwoorden: Nederlands; vloeken; schelden; ziektes; pandemie. 
DZIŚ ZNÓW JEST W CHOLERNIE ZŁYM HUMORZE, CO ZA ZARAZA!

O HISTORYCZNYM WPEYWIE PANDEMII NA HOLENDERSKIE PRZEKLEŃSTWA

\section{Streszczenie}

W najnowszej literaturze przedmiotu odnotowuje się wulgaryzację zachowań językowych współczesny człowiek coraz częściej przeklina. W zbiorze przekleństw swoistą podgrupę tworzą jednostki z określeniami chorób. Niniejszy artykuł ma na celu zbadanie wpływu minionych pandemii na język niderlandzki.

Słowa kluczowe: język niderlandzki; przeklinanie; inwektywy; choroby; pandemia.

TODAY, HE IS YET AGAIN IN A VERY BAD MOOD, WHAT A BASTARD HE IS! ON THE HISTORICAL INFLUENCE OF PANDEMICS ON PROFANITY IN DUTCH

\section{Sum mary}

Recent literature on politeness in language has observed that people are nowadays swearing more and use coarse language in which disease terms clearly prevail. This article aims to investigate the influence of past pandemics on Dutch. After a short historical introduction, the lexical traces of the various pandemics are discussed.

Keywords: Dutch; cursing; invectives; diseases; pandemics. 